\title{
Clinicopathologic distribution of KRAS and BRAF mutations in a Chinese population with colorectal cancer precursor lesions
}

\author{
Chenghao $\mathrm{Yi}^{1}{ }^{1,}$, Yanqing Huang ${ }^{1, *}$, Xing $\mathrm{Yu}^{1}$, Xiaofen $\mathrm{Li}^{1}$, Shu Zheng ${ }^{1}$, Kefeng Ding ${ }^{1,2}$ \\ and Jinghong $\mathrm{Xu}^{3}$ \\ ${ }^{1}$ Cancer Institute, Key Laboratory of Cancer Prevention and Intervention, China National Ministry of Education, The Second \\ Affiliated Hospital, School of Medicine, Zhejiang University, Hangzhou, China \\ 2 Department of Surgical Oncology, the Second Affiliated Hospital, School of Medicine, Zhejiang University, Hangzhou, China \\ ${ }^{3}$ Department of Pathology, the Second Affiliated Hospital, School of Medicine, Zhejiang University, Hangzhou, China \\ * Co-first authors have contributed equally to this study \\ Correspondence to: Jinghong Xu, email: zydxjh@zju.edu.cn
}

Kefeng Ding, email: dingkefeng@zju.edu.cn

Keywords: KRAS, BRAF, serrated lesion, conventional adenoma, colorectal cancer precursor lesions

Received: July 29, $2015 \quad$ Accepted: January 13, $2016 \quad$ Published: February 19, 2016

ABSTRACT

Investigating the clinical features and corresponding histomorphologic and molecular profiles of precursor lesions of colorectal cancer in a natural population provides new insights into the nature of colorectal cancer, uncovers new screening markers and establishes new prevention strategies for colorectal cancer. In this study, $\mathbf{4 3 0 2}$ patients with at least one colorectal polyp from a large colorectal cancer screening program were evaluated and genetic mutations in either KRAS or BRAF were detected in 495 patients. The population-based mutation rates of KRAS and BRAF genes in colorectal polyps within this Chinese patient population were $\mathbf{2 1 . 8 \%}$ and $12.1 \%$ respectively. Interestingly, considerable variability in the KRAS and BRAF mutations rates were found among different types of polyps. In a multivariate analysis, presence of villous histology and high-grade dysplasia was associated with KRAS mutations (OR, 3.0; 95\% CI, 1.7-5.4 and OR, 3.5; 95\% CI 1.9-6.5, respectively), while serrated adenomas and hyperplastic polyps were associated with BRAF V600E mutations (OR, 20.6; 95\% CI, 8.2-51.8 and OR, 11.9; 95\% CI 4.9-29.0, respectively). KRAS mutations may, in part, drive the histologic progression of adenomas toward a villous histology and higher grades of dysplasia. Mutant BRAF may, in part, drive the histologic progression of adenomas toward serrated histology. Dysplasia may arise from hyperplastic polyps, resulting in the formation of serrated adenomas and potentially the development of colorectal carcinoma.

\section{INTRODUCTION}

Colorectal cancer (CRC) is one of the leading causes of cancer death in the world, accounting for over 1.2 million new cancer cases and an estimated 608,700 deaths in 2012[1].

CRC develops through a stepwise evolution from normal mucosa to a precursor lesion and ultimately, a malignant tumor. Adenoma is the primary precursor lesion of CRC [2, 3]. Establishing a risk profile based on histomorphologic features of adenoma is not always straightforward. The addition of molecular profiling provides a more objective and reproducible approach for the classification of colorectal adenomas. The molecular mechanisms underlying the adenoma-carcinoma sequence has been extensively studied and involves a cumulative acquisition of mutations in tumor suppressor genes, such as $A P C$, and oncogenes such as KRAS and $B R A F$, leading to genomic instability [2, 4-6]. Both $K R A S$ and $B R A F$ encode kinases that belong to the mitogenactivated protein kinase $(M A P K)$ cascade that mediates cellular signaling involved in cell proliferation, apoptosis and differentiation [7]. In adenomas, mutations in $K R A S$ and $B R A F$ occur in early to advanced adenomas in the adenoma-to-carcinoma sequence. However, the specific role of $K R A S$ and $B R A F$ mutations in colorectal carcinogenesis remains controversial. 
Table 1: Characteristics of the $\mathbf{4 3 0 2}$ colorectal cancer precursor lesions from population-based screening

\begin{tabular}{|c|c|c|c|c|c|c|}
\hline & \multicolumn{3}{|c|}{ Conventional adenomas } & \multicolumn{2}{|c|}{ Serrated adenomas } & \multirow{2}{*}{ HGIN $(n \%)$} \\
\hline & TA $(n \%)$ & TVA $(n \%)$ & VA $(n \%)$ & SA $(n \%)$ & HPs $(n \%)$ & \\
\hline Total & $2816(65.6)$ & $463(10.8)$ & $22(0.5)$ & $85(2.0)$ & $765(17.8)$ & $151(3.5)$ \\
\hline \multicolumn{7}{|l|}{ gender } \\
\hline male & $1752(40.7)$ & $299(7.0)$ & 6 & $55(1.3)$ & 425(9.9) & $91(2.1)$ \\
\hline female & $1064(24.7)$ & $164(3.8)$ & $16(0.4)$ & $30(0.7)$ & $340(7.9)$ & $60(1.4)$ \\
\hline \multicolumn{7}{|l|}{ location } \\
\hline Right colon & $1096(25.5)$ & $136(3.2)$ & 6 & 17 & $217(5.0)$ & $38(0.9)$ \\
\hline Left colon & $1720(40.0)$ & $327(7.6)$ & 16 & $68(1.9)$ & $548(12.7)$ & $113(2.6)$ \\
\hline \multicolumn{7}{|l|}{ age } \\
\hline$<40$ & $31(0.7)$ & 3 & 0 & 0 & 10 & 0 \\
\hline $40-49$ & $490(11.4)$ & $69(1.6)$ & 1 & 13 & $152(3.5)$ & 16 \\
\hline $50-59$ & $976(22.7)$ & $150(3.5)$ & 8 & 29 & $266(6.2)$ & $50(1.2)$ \\
\hline $60-69$ & $995(23.1)$ & $171(4.0)$ & 12 & 34 & $259(6.2)$ & $66(1.5)$ \\
\hline $70-79$ & $308(7.2)$ & $66(1.5)$ & 1 & 8 & $74(1.7)$ & 16 \\
\hline$\geq 80$ & $16(0.4)$ & 4 & 0 & 1 & 4 & 3 \\
\hline
\end{tabular}

$\mathrm{TA}=$ Tubular adenoma, TVA $=$ Tubulovillous adenoma, $\mathrm{SA}=$ Serrated adenoma, VA= Villous adenoma, HPs= Hyperplastic polyps, HGIN= High grade intraepithelial neoplasia

Considering the wide divergence in the frequency of KRAS and BRAF mutations in the precursor lesions of $\mathrm{CRC}$ and the absence of data in the Chinese population, the aims of this study are to investigate the frequency of $K R A S$ and $B R A F$ mutations in precursor lesions of colorectal cancer in a Chinese population and to study the association between molecular alterations and histologic features.

\section{RESULTS}

\section{The clinicopathological characteristics of $\mathbf{4 3 0 2}$ patients}

In this study, the clinicopathologic features of 4302 $\mathrm{CRC}$ precursor lesions from a population-based screening was reviewed. In the 4302 patients, 2638 (61.3\%) were male, and 1674(38.7\%) were female. 748(17.4\%) lesions were located in the ascending colon, $762(17.7 \%)$ in the transverse colon, 491(11.4\%) in the descending colon, $1523(35.4 \%)$ in the sigmoid colon, and $778(18.1 \%)$ in the rectum. $764(17.8 \%)$ lesions were hyperplastic polyps while $3387(78.7 \%)$ lesions showed low grade dysplasia, and 151(3.5\%) showed high grade dysplasia. Among the 3387 lesions with low grade dysplasia, 2817(65.5\%) were tubular adenomas, 462(10.7\%) were tubulovillous adenomas, $85(2.0 \%)$ were serrated adenomas, and $22(0.5 \%)$ were villous adenomas. The characteristics of the colorectal cancer precursor lesions are summarized in Table 1.

\section{The clinicopathologic features of the selected patients}

A total of 495 subjects with at least one colorectal cancer precursor lesion were selected for genotyping of $K R A S$ and $B R A F$. Of the 495 subjects, 311 were male, and 184 were female. The patients' ages ranged from 20 to 88 years with the mean age of 60 years. There were $346(69.9 \%)$ lesions located in the left colon, 149(30.1\%) lesions located in the right colon, 65(13.1\%) hyperplastic polyps, $337(68.1 \%)$ low grade intraepithelial neoplasia, and 93(18.8\%) high grade intraepithelial neoplasia. In 337 low grade intraepithelial neoplasia, 155(31.3\%) were tubular adenomas, 123(24.8\%) were tubulovillous adenomas, 52(10.5\%) were serrated adenomas (44 were TSAs, and 8 were SSA/Ps), and 7(1.4\%) were villous adenomas.

\section{Distributions of KRAS mutations in the selected patients}

Among the 495 colorectal polyps and adenomas, 143 were identified as carrying KRAS codon 12 or 13 mutations, which was $28.9 \%$ of the total polyps and adenomas surveyed. In the 143 subjects with mutant KRAS, 93 (93/311, 29.9\%) were male, and 50 (50/184, $27.2 \%)$ were female. $46(46 / 149,30.9 \%)$ were located in the right colon, and $97(97 / 346,28.0 \%)$ were located in the left colon. $20(20 / 65,30.8 \%)$ were hyperplastic polyps, $85(85 / 337,25.2 \%)$ were low grade intraepithelial neoplasia, and $38(38 / 93,40.8 \%)$ were high grade intraepithelial neoplasia. In the low grade intraepithelial neoplasias with mutant $K R A S, 46(46 / 123,37.4 \%)$ were 
Table 2: Distributions of $K R A S$ mutations in the selected patients

\begin{tabular}{|c|c|c|c|c|}
\hline Clinical characteristic & $n$ & \begin{tabular}{|l|}
$K R A S$ mutation \\
$(\mathrm{n} \%)$
\end{tabular} & \begin{tabular}{|l|l}
$\begin{array}{l}\text { Univariate OR } \\
(95 \% \mathrm{CI})\end{array}$ \\
\end{tabular} & Multivariate OR $(95 \% \mathrm{CI})$ \\
\hline Total & 495 & $143(28.9 \%)$ & & \\
\hline \multicolumn{5}{|l|}{ gender } \\
\hline women & 184 & $50(27.1 \%)$ & 1(reference) & 1(reference) \\
\hline men & 311 & 93(29.9\%) & $1.1(0.8-1.7)$ & $1.2(0.8-1.8)$ \\
\hline \multicolumn{5}{|l|}{ age } \\
\hline$\leq 53$ & 137 & $27(19.7 \%)$ & 1(reference) & 1(reference) \\
\hline $54-60$ & 124 & $36(29.0 \%)$ & $1.7(1.0-3.0)$ & $1.6(0.9-3.0)$ \\
\hline $61-66$ & 119 & $46(38.6 \%)$ & $2.6(1.5-4.5)$ & $2.3(1.3-4.1)$ \\
\hline$>66$ & 115 & $33(28.6 \%)$ & $1.6(0.9-2.9)$ & $1.5(0.8-2.7)$ \\
\hline \multicolumn{5}{|l|}{ location } \\
\hline Right colon & 149 & $46(30.9 \%)$ & 1(reference) & 1(reference) \\
\hline Left colon & 346 & $97(28.0 \%)$ & $0.9(0.6-1.3)$ & $0.9(0.5-1.4)$ \\
\hline \multicolumn{5}{|l|}{ histology } \\
\hline TA & 155 & $24(15.5 \%)$ & 1(reference) & 1(reference) \\
\hline TVA & 123 & $46(37.4 \%)$ & $3.3(1.8-5.8)$ & $3.0(1.7-5.4)$ \\
\hline SA & 52 & $12(23.1 \%)$ & $1.6(0.8-3.6)$ & \begin{tabular}{|l|}
$1.5(0.7-3.2)$ \\
\end{tabular} \\
\hline VA & 7 & $3(43.0 \%)$ & $4.1(0.9-19.4)$ & $3.8(0.8-18.4)$ \\
\hline HPs & 65 & $20(30.8 \%)$ & $2.4(1.2-4.8)$ & $2.3(1.2-4.6)$ \\
\hline HGIN & 93 & $38(40.9 \%)$ & $3.8(2.1-6.9)$ & $3.5(1.9-6.5)$ \\
\hline
\end{tabular}

$\mathrm{TA}=$ Tubular adenoma, $\mathrm{TVA}=$ Tubulovillous adenoma, $\mathrm{SA}=$ Serrated adenoma, VA= Villous adenoma, HPs $=$ Hyperplastic polyps, HGIN= High grade intraepithelial neoplasia

Table 3: Distributions of different type mutations of $K R A S$

\begin{tabular}{|l|l|l|l|}
\hline Codon12(AA) & Codon13(AA) & Mutation type & $n \%$ \\
\hline Single mutations & & transition & $62(43.4 \%)$ \\
\hline GAT(Asp) & & transversion & $27(18.9 \%$ \\
\hline GTT(Val) & & transversion & $8(5.6 \%)$ \\
\hline TGT(Cys) & & transversion & $4(2.8 \%)$ \\
\hline GCT (Ala) & GAC (Asp) & transition & $28(19.6 \%)$ \\
\hline & TGC (Cys) & transversion & $1(0.7 \%)$ \\
\hline & AGC (13Ser) & transversion & $1(0.7 \%)$ \\
\hline \multicolumn{5}{|l|}{} & Transition & $6(4.2 \%)$ \\
\hline Double mutations & GAC (Asp) & Transition/ transversion & $3(2.1 \%)$ \\
\hline GAT(Asp) & & transversion & $1(0.7 \%)$ \\
\hline GAT;GTT(Asp; Val) & & Transition/ transversion & $1(0.7 \%)$ \\
\hline AGT;GCT(Ser;Ala) & & Transition/ transversion & $1(0.7 \%)$ \\
\hline GAT;GCT(Asp; Ala) & & & \\
\hline GAT(Asp) & TGC (Cys) &
\end{tabular}

$\mathrm{AA}=$ amino acids

tubulovillous adenomas, 24(24/155,15.5\%) were tubular adenomas, 12(12/52,23.1\%)were serrated adenomas, and $3(3 / 7,42.9 \%)$ were villous adenomas (Table 2 ).

\section{Distribution of different KRAS mutations}

Of the 143 adenomas with KRAS mutations, 101 $(70.6 \%)$ had a single mutation at codon $12 ; 30(21.0 \%)$ had a single mutation at codon 13; and $12(8.4 \%)$ had 2 different KRAS mutations. Of the 155 KRAS mutations identified, 97 (62.6\%) were transitions and 58 (37.4\%) were transversions. The most common single mutation was a GGT to a GAT transition in codon 12 that resulted in a change from the amino acid glycine to aspartic acid. This particular mutation occurred in $43.4 \%$ of the colorectal cancer precursor lesions with KRAS mutations (Table 3). 
Table 4: Distributions of $B R A F$ mutations in the selected patients

\begin{tabular}{|c|c|c|c|c|}
\hline Clinical characteristic & $n$ & $\begin{array}{l}B R A F \text { mutation } \\
(n \%)\end{array}$ & \begin{tabular}{|l|}
$\begin{array}{l}\text { Univariate OR } \\
(95 \% \mathrm{CI})\end{array}$
\end{tabular} & Multivariate OR $(95 \% \mathrm{CI})$ \\
\hline Total & 495 & $143(28.9 \%)$ & & \\
\hline \multicolumn{5}{|l|}{ sex } \\
\hline women & 184 & $32(17.4 \%)$ & 1(reference) & 1(reference) \\
\hline men & 311 & $45(14.4 \%)$ & $0.8(0.5-1.3)$ & $0.7(0.4-1.2)$ \\
\hline \multicolumn{5}{|l|}{ age } \\
\hline$\leq 53$ & 137 & $15(10.9 \%)$ & 1(reference) & 1(reference) \\
\hline$\overline{54-60}$ & 124 & $24(19.4 \%)$ & $1.4(0.7-2.8)$ & $1.8(0.8-4.0)$ \\
\hline $61-66$ & 119 & $21(17.6 \%)$ & $1.4(0.7-2.8)$ & $1.3(0.6-3.0)$ \\
\hline$>66$ & 115 & $17(14.8 \%)$ & $1.1(0.5-2.1)$ & $1.0(0.4-2.2)$ \\
\hline \multicolumn{5}{|l|}{ location } \\
\hline Right colon & 149 & $18(12.1 \%)$ & 1(reference) & 1 (reference) \\
\hline Left colon & 346 & $59(17.1 \%)$ & $1.5(0.85-2.6)$ & $1.6(0.9-2.7)$ \\
\hline \multicolumn{5}{|l|}{ histology } \\
\hline TA & 155 & $8(5.2 \%)$ & 1(reference) & 1(reference) \\
\hline TVA & 123 & $10(8.1 \%)$ & $1.5(0.6-4.3)$ & $1.8(0.7-4.7)$ \\
\hline $\mathrm{SA}$ & 52 & $26(50.0 \%)$ & $18.4(7.5-45)$ & $20.6(8.2-51.8)$ \\
\hline VA & 7 & $4(57.0 \%)$ & $24.5(4.7-128.5)$ & $26.2(4.7-144.2)$ \\
\hline HPs & 65 & $24(36.9 \%)$ & $10.8(4.5-25.7)$ & $11.9(4.9-29.0)$ \\
\hline HGIN & 93 & $5(5.3 \%)$ & $1.0(0.3-3.3)$ & $1.1(0.3-3.5)$ \\
\hline
\end{tabular}

$\mathrm{TA}=$ Tubular adenoma, $\mathrm{TVA}=$ Tubulovillous adenoma, $\mathrm{SA}=$ Serrated adenoma, VA= Villous adenoma, HPs $=$ Hyperplastic polyps, HGIN= High grade intraepithelial neoplasia

Table 5: Distributions characteristic of $K R A S$ and $B R A F$

\begin{tabular}{|l|l|l|l|l|l|l|l|l|}
\hline \multirow{2}{*}{} & \multirow{2}{*}{ Total } & \multicolumn{2}{l|}{ Conventional adenomas } & \multicolumn{2}{l|}{ Serrated lesions } & \multirow{2}{*}{ HGIN } \\
\cline { 3 - 8 } & & TA & TVA & VA & TSA & SSA/P & HPs & \\
\hline Total & 495 & 155 & 123 & 7 & 44 & 8 & 65 & 93 \\
\hline $\begin{array}{l}\text { KRAS } \\
\text { mutations }\end{array}$ & $143(28.9 \%)$ & $24(15.5 \%)$ & $46(37.4 \%)$ & 3 & $11(25.0 \%)$ & 1 & $20(30.8 \%$ & $38(40.9 \%)$ \\
\hline $\begin{array}{l}\text { BRAF } \\
\text { mutations }\end{array}$ & $77(15.5 \%)$ & $8(5.2 \%)$ & $10(8.1 \%)$ & 4 & $20(45.5 \%)$ & 6 & $24(36.9 \%)$ & $5(5.4 \%)$ \\
\hline
\end{tabular}

$\mathrm{TA}=$ Tubular adenoma, $\mathrm{TVA}=$ Tubulovillous adenoma, $\mathrm{VA}=$ Villous adenoma, $\mathrm{TSA}=$ Traditional serrated adenoma, $\mathrm{SSA} / \mathrm{P}=$ Sessile serrated adenoma/polyp, HPs= Hyperplastic polyps, HGIN= High grade intraepithelial neoplasia

$K R A S$ mutation present in $25.6 \%$ traditional adenomas and $27.4 \%$ serrated adenomas, $B R A F$ mutation present in $7.1 \%$ traditional adenomas and $42.7 \%$ serrated adenomas. In the multivariate analyses, presence of villous histology and highgrade dysplasia independently associated with $K R A S$ mutations $(\mathrm{OR}, 3.0$; 95\% CI, 1.7-5.0 and OR, 3.5; 95\% CI 1.5-6.4, respectively), presence of serrated histology and hyperplastic polyps independently associated with $B R A F$ V600E mutations (OR, 20.6; 95\% CI, 8.2-51.8 and OR, 11.9; 95\% CI 4.9-29.0, respectively).

\section{Univariate OR and Multivariate OR for KRAS mutations}

There were no differences in the prevalence of $K R A S$ mutations by gender as well as by location of the colorectal cancer precursor lesions (Table 2). Older participants were more likely to have a precursor lesion with a $K R A S$ mutation $(24.5 \%$ in $<60$ vs $33.1 \%$ in $\geq 60$, $P=0,04)$. A strong relationship was found between $K R A S$ mutations and precursor lesion histology. KRAS mutations were present in $38.8 \%$ of the adenomas that were tubulovillous or villous compared with $15.5 \%$ of adenomas that were of tubular histology. Tubulovillous and villous adenomas were combined for this analysis because there were only 7 purely villous adenomas in the study for separate analyses, but the frequency of mutations in the 7 villous adenomas was $42.9 \%$. KRAS mutations presented in $40.9 \%$ of adenomas that were graded as having high-grade dysplasia, but only in $25.2 \%$ of adenomas with low-grade dysplasia.

In the multivariate analyses (Table 2), presence of villous histology and high-grade dysplasia remained significantly and independently associated with KRAS mutations (OR, 3.0; 95\% CI, 1.7-5.4 and OR, 3.5; 95\% CI 1.9-6.5, respectively). 


\section{Distribution of BRAF mutations in the selected patients}

A total of 77 colorectal cancer precursor lesions were identified with $B R A F$ V600E mutations, 45 from male subjects, and 32 from female subjects. 18(18/149,12.1\%) were located in the right colon, 59(59/346,17.1\%) were located in the left colon. 24(24/65, 36.9\%) were hyperplastic polyps, 48 were low grade intraepithelial neoplasia, and 5 were high grade intraepithelial neoplasia. In low grade intraepithelial neoplasia with mutant $B R A F, 10$ were tubulovillous adenomas, 8 were tubular adenomas, 26(26/52,50.0\%) were serrated adenomas, and $4(4 / 7,57.1 \%)$ were villous adenomas.

Of the $77 B R A F$ V600E mutations, $64.9 \%$ (50/77) present in serrated lesions $(50.0 \%$ in serrated adenomas and $36.9 \%$ in hyperplastic polyps). There were only $7.1 \%$ (27/378) BRAF V600E mutations present in other types of colorectal adenomas (tubular, tubulovillous and villous adenomas). We found only $5 B R A F$ V600E mutations present in high grade intraepithelial neoplasia.

\section{Univariate $O R$ and multivariate $O R$ for BRAF mutations}

There were no differences in the prevalence of $B R A F$ mutations by gender, age or location of precursor lesions. In the multivariate analyses (Table 4), the presence of serrated histology and hyperplastic polyps remained significantly and independently associated with $B R A F$ V600E mutations (OR, 20.6; 95\% CI, 8.2-51.8 and OR, 11.9 ; 95\% CI 4.9-29.0, respectively).

We found 7 patients with both KRAS codons 12 and 13 mutations as well as $B R A F \mathrm{~V} 600 \mathrm{E}$ mutations within the same precursor lesion.

\section{DISCUSSIONS}

Several risk factors for colorectal cancer have been identified by epidemiologic studies, including characteristics of both the host (age, gender, race, and family cancer history) [8,9] and the environment (consumption of red and processed meats, smoking, alcohol consumption, diabetes mellitus, low level of physical activity and obesity)[10-17]. Similarly, several characteristics of colorectal cancer precursor lesions (size, location, histology, and degree of dysplasia) have been found to be associated with an increased risk of precursor progression to carcinoma $[18,19]$. In parallel, numerous studies have revealed that cancer results, in part, from the accumulation of genetic alterations, including activating mutations of proto-oncogenes, inactivating mutations of tumor suppressor and DNA repair genes, DNAmethylation and chromatin structure changes[20-22]. Relatively little is known about the relationship amongst host and environmental risk factors, colorectal cancer precursor lesions characteristics, and genetic events, and how they work together to drive the process of carcinogenesis.

$K R A S$ and $B R A F$ mutations occur relatively early in the adenoma-carcinoma process [23-26]. Somatic mutations that activate regulators and effectors of RAS proteins are common in tumor development [1-3]. In approximately $35.0 \%-42.0 \%$ of early colorectal cancer (CRC) patients, KRAS mutations inhibit KRAS GTPase, resulting in constitutive activation of $K R A S$, and in turn, activation of the $R A S / R A F$ signaling pathway. In CRC, $97.0 \%$ of $K R A S$ mutations occur in codons 12 and 13 of exon 2 [4]. BRAF is a human gene that encodes the oncoprotein $B R A F$, a serine/threonine protein kinase [5]. $B R A F$ is a member of the $R A F$ kinase family that regulates the $R A S / R A F / M E K /$ extracellular signal regulated kinase (ERK) pathway and is involved in cell division, differentiation, and secretion [6]. The most common $B R A F$ mutation is a missense mutation (V600E), resulting in the replacement of valine for glutamic acid which generates aberrant MEK/ERK signaling in CRC [7]. Numerous large studies have investigated the clinical significance of KRAS and BRAF mutations in CRC [4-6, 27-31], but the specific role of $K R A S$ and $B R A F$ mutations in colorectal carcinogenesis remains unclear. In this study, we investigated several aspects of the molecular epidemiology of $K R A S$ and $B R A F$ mutations in sporadic colorectal cancer precursor lesions.

Amongst the 4302 patients examined with at least one colorectal cancer precursor lesion, the male to female ratio was approximately1.6:1. Studies have indicated male hormones increase the incidence of colonic polyps $[32,33]$. The differences of lifestyle between genders including smoking and alcohol consumption may also contribute to this increased incidence in males [13, 19]. Amongst the adenomas examined, 491(11.4\%) were located in the descending colon, 1523(35.4\%) in the sigmoid colon, and $778(18.1 \%)$ in the rectum. This data reveals that the majority of precursor lesions are located in the left colon $(64.9 \%)$ as similarly reported in previous studies [18, 34, 35]. Histopathologic subtyping of these precursor lesions revealed that tubular and tubulovillous adenomas accounted for 76.2\% (3279/4302), while hyperplastic polyps and serrated adenomas accounted for $19.3 \%$ (849/4302). There were $8 \mathrm{SSA} / \mathrm{Ps}$ amongst the 495 patients. Previous studies from a Western population showed that SSAs constitute approximately $9.0 \%$ of all polyps and $22.0 \%$ of serrated polyps $[36,37]$. Thus, the proportion of SSAs in the present study is much lower in comparison to that in Western patients. A lower proportion of SSAs in the Chinese population has been reported by Qiu et al (SSAs accounted for $4.9 \%$ of serrated polyps and $1.0 \%$ of all colorectal polyps according to their data) [38]. This great variation in SSA/P detection rates between this and previous studies can be caused by genetic factors, 
lifestyle and dietary factors amongst the different patient populations.

We found that $28.9 \%$ of the 495 colorectal cancer precursor lesions had mutations in the KRAS gene which was in range with the $15.0 \%-75.0 \%$ prevalence of $K R A S$ mutations in polyps reported in previous studies[39-51]. It is likely that this wide range reflects differences in race and patient selection. The KRAS mutation rate in our study was approximately $21.8 \%$ by standardized rate which is similar to the result of Nusko et al[46].

We found that individuals over the age of 60 years had about a 1.3-fold increase in risk of having a $K R A S$ mutant colorectal cancer precursor lesion than younger individuals in a univariate analysis. However the multivariate analysis showed that age was not an independent predictor for KRAS mutation in colorectal cancer precursor lesions. The absolute frequency of KRAS mutations in right colon lesions is higher than that in the left $(30.9 \%$ v $28.0 \%)$, but this difference did not reach statistical significance $(P=0.52)$.

In our univariate analysis, villous histology and high grade dysplasia are each significantly associated with $K R A S$ mutations. The result is similar to Maltzman $\mathrm{T}$ et al [50]. A strong association between KRAS mutations and both villous histology and high grade dysplasia persisted after multivariate analysis of our data. These observations suggest the possibility that $K R A S$ mutations may, in part, drive the histologic progression of adenomas toward a villous histology and higher grades of dysplasia.

In our data, $B R A F$ mutations were detected in $50.0 \%$ of serrated adenomas, $36.9 \%$ of hyperplastic polyps and $7.1 \%$ of other types of colorectal cancer precursor lesions. The BRAF mutation rates in serrated adenomas and hyperplastic polyps were lower than that reported in previous studies [37, 45, 51-55]. The overall $B R A F$ mutation rate in colorectal cancer precursor lesions in this studied population was $12.1 \%$ by standardized rate, similar to previous studies[56, 57]. A strong association was found between BRAF mutations and both serrated adenomas and hyperplastic polyps during multivariate analysis. The similar BRAF mutation rates between serrated adenomas and hyperplastic polyps suggests that dysplasia may arise from hyperplastic polyps, resulting in the formation of serrated adenomas and potentially the development of colorectal carcinoma.

The traditional view of hyperplastic polyps (HPs) is that they are relatively common, non-neoplastic lesions that may be safely ignored and are distinctly separate from the smaller category of neoplastic polyps and precancerous adenomas [58]. There were 65 hyperplastic polyps in our study with $39(60.0 \%)$ located in the sigmoid colon and rectum. We found $20 K R A S$ mutations and $24 B R A F$ mutations in these 65 hyperplastic polyps. On histopathologic examination, hyperplastic polyps show a serrated morphology $[59,60]$. In cancer progression, molecular changes tend to precede morphologic changes.
Although dysplasia is not seen in hyperplastic polyps, it would be interesting to further evaluate the relationship between HPs and serrated adenoma in future studies.

The characteristic distribution of $K R A S$ and $B R A F$ mutations suggest there may be two different pathways in adenoma to adenocarcinoma progression. The first pathway is a traditional adenoma-carcinoma sequence involving KRAS mutations. Mutant KRAS may, in part, drive the histologic progression of adenomas toward villous histology and higher grades of dysplasia. Another proposed pathway is a serrated adenomacarcinoma sequence. The polyps of this pathway would differ morphologically and genetically from those of a traditional adenoma-carcinoma sequence. Mutant $B R A F$ may, in part, drive the histologic progression of adenomas toward serrated histology. In turn, the proposed two different adenoma-carcinoma sequences would then likely result in potentially different colorectal carcinoma subtypes. In the 2012 Cancer Genome Atlas Network study [61], KRAS mutations presented in $43.0 \%$ of non-hypermutated colorectal cancers and $30.0 \%$ of hypermutated colorectal cancers while, $B R A F$ mutations presented in $3.0 \%$ of non-hypermutated colorectal cancers and $47.0 \%$ of hypermutated colorectal cancers. We found striking similarities between colorectal cancers and adenomas during the evaluation of $K R A S$ and $B R A F$ mutations (Table 5). Therefore, we propose a traditional adenoma-carcinoma sequence results in non-hypermutated colorectal cancers while a serrated adenoma-carcinoma sequence results in hypermutated colorectal cancers. Further investigation is needed to validate this hypothesis and support the preliminary data presented in this study.

Currently, the treatment decisions of colorectal cancer is based on the TNM classification system which ignores molecular findings. The prognosis of colorectal cancer patients may be improved by taking into consideration molecular pathological features and biological characteristics of different colorectal cancer subtypes.

\section{SUMMARY}

The process of carcinogenesis is thought to be driven, in part, by sequential rounds of mutations followed by clonal expansion. The final histologic and biologic features of adenomas are the result of the accumulation of a series of molecular events. Knowledge of the mutational profile of a precancerous lesion may be expected to provide greater insight into its clinical behavior in comparison to histology or size of the lesion. The present study has several clinical implications. It provides a molecular basis for the clinical observations that hyperplastic polyps may have malignant potential. Furthermore, $K R A S$ and $B R A F$ are likely involved in the malignant transformation of colorectal adenomas as driver genes. In the future, KRAS and $B R A F$ may serve as molecular markers for colorectal 
screening and molecular typing as well as potential targets for therapeutic intervention.

\section{MATERIALS AND METHODS}

\section{Patients}

The patients were recruited from a populationbased colorectal cancer screening program. A total of 87254 subjects between 40 to 74 years old were screened by questionnaire-based risk assessment and fecal immunochemical testing from May 2011 to April 2014. Among them, a total of 4302 subjects with at least one CRC precursor lesions were accepted for endoscopic resection. Hematoxylin and Eosin (H\&E)-stained slides from formalin-fixed paraffin-embedded (FFPE) lesion samples $(n=4302)$ were reviewed by pathologists. In the 4302 lesions, 495 lesions were selected and analyzed for $K R A S$ and BRAF genotyping. The right colon was from ileocecal valve to splenic flexure of the colon. The left colon was from the splenic flexure of colon to rectum. This study was approved by the Committee for the Protection of Human Subjects at the Second Affiliated Hospital, School of Medicine, Zhejiang University.

\section{DNA extraction}

Genomic DNA from 495 precursor lesions of CRC samples was extracted from freshly cut formalin-fixed, paraffin-embedded tissue sections (five $10-\mu \mathrm{m}$ sections) using a QIAamp DNA FFPE Tissue Kit (Qiagen, Hilden, Germany) according to the manufacturer's instructions. The lesion area was identified through haematoxylin-eosin staining, and tissue from this area on unstained sections was removed for DNA extraction into microcentrifuge tubes.

\section{Analysis of KRAS and BRAF mutations}

To detect genetic alterations in KRAS and $B R A F$, we analyzed the point mutations of codons 12 and 13 in the KRAS gene and the mutation of exon 15 codon 600 in the $B R A F$ gene by direct sequencing. The primers for $K R A S$ sequencing of codons 12 and 13 were as follows: 5'GGTACTGGAGTATTTGAT-3' (forward) and 5' TTGTGGACGAATATGATCCAACA-3' (reverse). The primers for sequencing the $B R A F$ exon 15 codon 600 were as follows: 5-TCATAATGCTTGCTCTGATAGGA-3 (forward) and 5'-TCCACTGATTAAATTTTTGGCC-3 (reverse).

Amplification of codons 12 and 13 of KRAS gene and the exon 15 codon 600 of $B R A F$ gene was carried out in a Touchgene Gradient Thermal Cycler (Techne Inc.,
Princeton, NJ) in a $25 \mu \mathrm{l}$ PCR reaction mixture containing $1 \mu \mathrm{l}$ genomic DNA, $1 \mu \mathrm{l}$ forward primers, $1 \mu \mathrm{l}$ reverse primers, $12.5 \mu 1$ KAPA2G (KAPA2G, Wilmington, MA) Fast Multiplex Mix and $9.5 \mu \mathrm{lddH_{2 }} O$.

The PCR reaction for codons 12 and 13 of the KRAS gene was as follows: $94^{\circ} \mathrm{C}, 5$ minutes; and 30 cycles of $94^{\circ} \mathrm{C}, 30$ seconds; $56^{\circ} \mathrm{C}, 30$ seconds; $72^{\circ} \mathrm{C}, 1$ minute; and $72^{\circ} \mathrm{C}, 5$ minutes. The 201 base pair PCR product was then visualized on a $2.0 \%$ agarose gel. DNA samples that failed to amplify with $1 \mu \mathrm{l}$ were repeated using $5 \mu \mathrm{l}$ of the extracted DNA. The PCR reaction for the exon 15 codon 600 of $B R A F$ gene was as follows: $94^{\circ} \mathrm{C}, 5$ minutes; and 30 cycles of $94^{\circ} \mathrm{C}, 30$ seconds; $55^{\circ} \mathrm{C}, 30$ seconds; $72^{\circ} \mathrm{C}$, 1 minute; and $72^{\circ} \mathrm{C}, 5$ minutes. The 215 base pair PCR product was then visualized on a $2.0 \%$ agarose gel. DNA samples that failed to amplify with $1 \mu \mathrm{l}$ were repeated using $5 \mu \mathrm{l}$ of the extracted DNA. For each set of samples extracted, negative control tubes containing no tissue were simultaneously extracted and tested for ability to amplify a product. Known positive and negative control samples were regularly analyzed.

Direct sequencing was performed using an $\mathrm{ABI}$ 3730XL DNA Analyzer (Applied Biosystems, Foster City, California, USA). PCR and sequence analysis of mutated samples were repeated twice to exclude PCR errors.

\section{Statistical analysis}

The relationship between KRAS codon 12 or 13 mutations and $B R A F \mathrm{~V} 600 \mathrm{E}$ in colorectal cancer precursor lesions and various characteristics of patients and corresponding lesions were assessed by both univariate and multiple logistical analysis using IBM SPSS software for Windows, version 19.0 (IBM Corporation, Armonk, New York). Odds ratios (ORs) were first calculated separately for all of the independent variables (patient and adenoma characteristics) with $K R A S$ and $B R A F$ mutational status (wild-type $v s$. mutant) as the independent variable. Multiple logistic models that included all lesions or all patient characteristics were then performed for both specimens-based and patients-based analysis. Multiple logistic regression models of specimens-based analysis were estimated using generalized estimating equations to allow potential correlation among the adenomas within the same individual. Standardized rate was used to estimate the mutation rate of KRAS and BRAF in population. The number of decimal places in percentages was set to one.

\section{ACKNOWLEDGMENTS}

The study was supported by The National HighTechnology Research and Development Program ("863"Program) of China, No. 2012AA02A506, the Zhejiang Provincial Natural Science Foundation of China, No. LY13H160017, National Natural Science Foundation 
of China (No. 81272455, 81472664 ) and the Public Welfare in Health Industry, 2014, Health Ministry of China (NO. 201402015). There is no grant from the NIH.

\section{CONFLICTS OF INTEREST}

The authors declare no conflict of interests.

\section{REFERENCES}

1. Jemal A, Bray F, Center MM, Ferlay J, Ward E and Forman D. Global cancer statistics. CA: a cancer journal for clinicians. 2011; 61:69-90.

2. Fearon ER and Vogelstein B. A genetic model for colorectal tumorigenesis. Cell. 1990; 61:759-767.

3. Lieberman DA, Weiss DG, Bond JH, Ahnen DJ, Garewal H and Chejfec G. Use of colonoscopy to screen asymptomatic adults for colorectal cancer. Veterans Affairs Cooperative Study Group 380. The New England journal of medicine. 2000; 343:162-168.

4. Bronte G, Silvestris N, Castiglia M, Galvano A, Passiglia F, Sortino G, Cicero G, Rolfo C, Peeters M, Bazan V, Fanale D, Giordano A and Russo A. New findings on primary and acquired resistance to anti-EGFR therapy in metastatic colorectal cancer: do all roads lead to RAS? Oncotarget. 2015; 22; 6:24780-96. doi: 10.18632/oncotarget.4959.

5. Morkel M, Riemer P, Blaker H and Sers C. Similar but different: distinct roles for KRAS and BRAF oncogenes in colorectal cancer development and therapy resistance. Oncotarget. 2015; 6:20785-800. doi: 10.18632/ oncotarget. 4750 .

6. Boleij A, Tops BB, Rombout PD, Dequeker EM, Ligtenberg MJ, van Krieken JH and Dutch Ras Eqa I. RAS testing in metastatic colorectal cancer: excellent reproducibility amongst 17 Dutch pathology centers. Oncotarget. 2015; 6:15681-15689. doi: 10.18632/oncotarget.3804.

7. Sebolt-Leopold JS and Herrera R. Targeting the mitogenactivated protein kinase cascade to treat cancer. Nature reviews Cancer. 2004; 4:937-947.

8. Bonelli L, Martines H, Conio M, Bruzzi P and Aste H. Family history of colorectal cancer as a risk factor for benign and malignant tumours of the large bowel. A casecontrol study. International journal of cancer. 1988; 41:513517.

9. Hemminki K and Eng C. Clinical genetic counselling for familial cancers requires reliable data on familial cancer risks and general action plans. Journal of medical genetics. 2004; 41:801-807.

10. Larsson SC, Orsini N and Wolk A. Diabetes mellitus and risk of colorectal cancer: a meta-analysis. Journal of the National Cancer Institute. 2005; 97:1679-1687.

11. Huxley RR, Ansary-Moghaddam A, Clifton P, Czernichow S, Parr CL and Woodward M. The impact of dietary and lifestyle risk factors on risk of colorectal cancer: a quantitative overview of the epidemiological evidence. International journal of cancer Journal. 2009; 125:171-180.

12. Alexander DD, Weed DL, Cushing CA and Lowe KA. Meta-analysis of prospective studies of red meat consumption and colorectal cancer. Eur J Cancer Prev. 2011; 20:293-307.

13. Fedirko V, Tramacere I, Bagnardi V, Rota M, Scotti L, Islami F, Negri E, Straif K, Romieu I, La Vecchia C, Boffetta $\mathrm{P}$ and Jenab M. Alcohol drinking and colorectal cancer risk: an overall and dose-response meta-analysis of published studies. Annals of oncology. 2011; 22:19581972.

14. Magalhaes B, Peleteiro B and Lunet N. Dietary patterns and colorectal cancer: systematic review and meta-analysis. Eur J Cancer Prev. 2012; 21:15-23.

15. Johnson CM, Wei C, Ensor JE, Smolenski DJ, Amos CI, Levin B and Berry DA. Meta-analyses of colorectal cancer risk factors. Cancer causes \& control. 2013; 24:1207-1222.

16. Kitahara CM, Berndt SI, de Gonzalez AB, Coleman HG, Schoen RE, Hayes RB and Huang WY. Prospective investigation of body mass index, colorectal adenoma, and colorectal cancer in the prostate, lung, colorectal, and ovarian cancer screening trial. Journal of clinical oncology. 2013; 31:2450-2459.

17. Parajuli R, Bjerkaas E, Tverdal A, Selmer R, Le Marchand L, Weiderpass E and Gram IT. The increased risk of colon cancer due to cigarette smoking may be greater in women than men. Cancer epidemiology, biomarkers \& prevention. 2013; 22:862-871.

18. Chen HM, Weng YR, Jiang B, Sheng JQ, Zheng P, Yu CG and Fang JY. Epidemiological study of colorectal adenoma and cancer in symptomatic patients in China between 1990 and 2009. J Dig Dis. 2011; 12:371-378.

19. Cao Y, Rosner BA, Ma J, Tamimi RM, Chan AT, Fuchs $\mathrm{CS}, \mathrm{Wu} \mathrm{K}$ and Giovannucci EL. Assessing individual risk for high-risk colorectal adenoma at first-time screening colonoscopy. International journal of cancer. 2015.

20. Cho KR and Vogelstein B. Genetic alterations in the adenoma-carcinoma sequence. Cancer. 1992; 70:17271731.

21. Fearon ER. Molecular genetics of colorectal cancer. Annual review of pathology. 2011; 6:479-507.

22. Bogaert $\mathrm{J}$ and Prenen $\mathrm{H}$. Molecular genetics of colorectal cancer. Annals of gastroenterology. 2014; 27:9-14.

23. Stopera SA, Murphy LC and Bird RP. Evidence for a ras gene mutation in azoxymethane-induced colonic aberrant crypts in Sprague-Dawley rats: earliest recognizable precursor lesions of experimental colon cancer. Carcinogenesis. 1992; 13:2081-2085.

24. Pretlow TP and Pretlow TG. Mutant KRAS in aberrant crypt foci (ACF): initiation of colorectal cancer? Biochimica et biophysica acta. 2005; 1756:83-96.

25. Rosenberg DW, Yang S, Pleau DC, Greenspan EJ, Stevens RG, Rajan TV, Heinen CD, Levine J, Zhou Y and 
O'Brien MJ. Mutations in BRAF and KRAS differentially distinguish serrated versus non-serrated hyperplastic aberrant crypt foci in humans. Cancer research. 2007; 67:3551-3554.

26. Langner C. Serrated and non-serrated precursor lesions of colorectal cancer. Dig Dis. 2015; 33:28-37.

27. Pricolo VE, Finkelstein SD, Wu TT, Keller G, Bakker A, Swalsky PA and Bland KI. Prognostic value of TP53 and K-ras-2 mutational analysis in stage III carcinoma of the colon. American journal of surgery. 1996; 171:41-46.

28. Ahnen DJ, Feigl P, Quan G, Fenoglio-Preiser C, Lovato LC, Bunn PA, Jr., Stemmerman G, Wells JD, Macdonald JS and Meyskens FL, Jr. Ki-ras mutation and p53 overexpression predict the clinical behavior of colorectal cancer: a Southwest Oncology Group study. Cancer research. 1998; 58:1149-1158.

29. Rowland A, Dias MM, Wiese MD, Kichenadasse G, McKinnon RA, Karapetis CS and Sorich MJ. Meta-analysis of BRAF mutation as a predictive biomarker of benefit from anti-EGFR monoclonal antibody therapy for RAS wild-type metastatic colorectal cancer. British journal of cancer. 2015; 112:1888-94.

30. Feng Q, Liang L, Ren L, Chen J, Wei Y, Chang W, Zhu D, Lin Q, Zheng P and Xu J. A specific KRAS codon 13 mutation is an independent predictor for colorectal cancer metachronous distant metastases. American journal of cancer research. 2015; 5:674-688.

31. Schirripa M, Bergamo F, Cremolini C, Casagrande M, Lonardi S, Aprile G, Yang D, Marmorino F, Pasquini G, Sensi E, Lupi C, De Maglio G, Borrelli N, Pizzolitto S, Fasola G, Bertorelle R, et al. BRAF and RAS mutations as prognostic factors in metastatic colorectal cancer patients undergoing liver resection. British journal of cancer. 2015; 112:1921-8.

32. Peipins LA, Newman B and Sandler RS. Reproductive history, use of exogenous hormones, and risk of colorectal adenomas. Cancer epidemiology, biomarkers \& prevention. 1997; 6:671-675.

33. Amos-Landgraf JM, Heijmans J, Wielenga MC, Dunkin E, Krentz KJ, Clipson L, Ederveen AG, Groothuis PG, Mosselman S, Muncan V, Hommes DW, Shedlovsky A, Dove WF and van den Brink GR. Sex disparity in colonic adenomagenesis involves promotion by male hormones, not protection by female hormones. Proceedings of the National Academy of Sciences of the United States of America. 2014; 111:16514-16519.

34. Almadi MA, Alharbi O, Azzam N, Wadera J, Sadaf N and Aljebreen AM. Prevalence and characteristics of colonic polyps and adenomas in 2654 colonoscopies in Saudi Arabia. Saudi journal of gastroenterology. 2014; 20:154161.

35. Visovan, II, Tantau M, Ciobanu L, Pascu O and Tantau A. Increasing prevalence of right-sided colonic adenomas in a high-volume endoscopy department in Romania: implications for colorectal cancer screening. Journal of gastrointestinal and liver diseases. 2014; 23:147-151.

36. Spring KJ, Zhao ZZ, Karamatic R, Walsh MD, Whitehall VL, Pike T, Simms LA, Young J, James M, Montgomery GW, Appleyard M, Hewett D, Togashi K, Jass JR and Leggett BA. High prevalence of sessile serrated adenomas with BRAF mutations: a prospective study of patients undergoing colonoscopy. Gastroenterology. 2006; 131:1400-1407.

37. Carr NJ, Mahajan H, Tan KL, Hawkins NJ and Ward RL. Serrated and non-serrated polyps of the colorectum: their prevalence in an unselected case series and correlation of BRAF mutation analysis with the diagnosis of sessile serrated adenoma. J Clin Pathol. 2009; 62:516-518.

38. Qiu Y, Fu X, Zhang W, Xu Y, Xiao L, Chen X, Shi L, Zhou $\mathrm{X}, \mathrm{Xia}$ G, Peng Y and Deng M. Prevalence and molecular characterisation of the sessile serrated adenoma in a subset of the Chinese population. Journal of clinical pathology. 2014; 67:491-498.

39. Vogelstein B, Fearon ER, Hamilton SR, Kern SE, Preisinger AC, Leppert M, Nakamura Y, White R, Smits $\mathrm{AM}$ and Bos JL. Genetic alterations during colorectal-tumor development. The New England journal of medicine. 1988; 319:525-532.

40. McLellan EA, Owen RA, Stepniewska KA, Sheffield JP and Lemoine NR. High frequency of K-ras mutations in sporadic colorectal adenomas. Gut. 1993; 34:392-396.

41. Ranaldi R, Gioacchini AM, Manzin A, Clementi M, Paolucci S and Bearzi I. Adenoma-carcinoma sequence of colorectum. Prevalence of K-ras gene mutation in adenomas with increasing degree of dysplasia and aneuploidy. Diagnostic molecular pathology. 1995; 4:198-202.

42. Ajiki T, Fujimori T, Ikehara H, Saitoh Y and Maeda S. K-ras gene mutation related to histological atypias in human colorectal adenomas. Biotechnic \& histochemistry. 1995; 70:90-94.

43. Norheim Andersen S, Breivik J, Lovig T, Meling GI, Gaudernack G, Clausen OP, Schjolberg A, Fausa O, Langmark F, Lund E and Rognum TO. K-ras mutations and HLA-DR expression in large bowel adenomas. British journal of cancer. 1996; 74:99-108.

44. Morris RG, Curtis LJ, Romanowski P, Hardcastle JD, Jenkins DA, Robinson M, Wyllie AH and Bird CC. Kiras mutations in adenomas: a characteristic of cancerbearing colorectal mucosa. The Journal of pathology. 1996; 180:357-363.

45. Jass JR, Baker K, Zlobec I, Higuchi T, Barker M, Buchanan $\mathrm{D}$ and Young J. Advanced colorectal polyps with the molecular and morphological features of serrated polyps and adenomas: concept of a 'fusion' pathway to colorectal cancer. Histopathology. 2006; 49:121-131.

46. Nusko G, Sachse R, Mansmann U, Wittekind C and Hahn EG. K-RAS-2 gene mutations as predictors of metachronous colorectal adenomas. Scand J Gastroenterol. 1997; 32:1035-1041. 
47. Ohnishi T, Tomita N, Monden T, Ohue M, Yana I, Takami K, Yamamoto H, Yagyu T, Kikkawa N, Shimano T and Monden M. A detailed analysis of the role of K-ras gene mutation in the progression of colorectal adenoma. British journal of cancer. 1997; 75:341-347.

48. Zhu D, Keohavong P, Finkelstein SD, Swalsky P, Bakker A, Weissfeld J, Srivastava S and Whiteside TL. K-ras gene mutations in normal colorectal tissues from K-ras mutationpositive colorectal cancer patients. Cancer research. 1997; 57:2485-2492.

49. Rashid A, Zahurak M, Goodman SN and Hamilton SR. Genetic epidemiology of mutated K-ras proto-oncogene, altered suppressor genes, and microsatellite instability in colorectal adenomas. Gut. 1999; 44:826-833.

50. Maltzman T, Knoll K, Martinez ME, Byers T, Stevens BR, Marshall JR, Reid ME, Einspahr J, Hart N, Bhattacharyya AK, Kramer CB, Sampliner R, Alberts DS and Ahnen DJ. $\mathrm{Ki}$-ras proto-oncogene mutations in sporadic colorectal adenomas: relationship to histologic and clinical characteristics. Gastroenterology. 2001; 121:302-309.

51. Yuen ST, Davies H, Chan TL, Ho JW, Bignell GR, Cox C, Stephens P, Edkins S, Tsui WW, Chan AS, Futreal PA, Stratton MR, Wooster R and Leung SY. Similarity of the phenotypic patterns associated with BRAF and KRAS mutations in colorectal neoplasia. Cancer research. 2002; 62:6451-6455.

52. Kambara T, Simms LA, Whitehall VL, Spring KJ, Wynter $\mathrm{CV}$, Walsh MD, Barker MA, Arnold S, McGivern A, Matsubara N, Tanaka N, Higuchi T, Young J, Jass JR and Leggett BA. BRAF mutation is associated with DNA methylation in serrated polyps and cancers of the colorectum. Gut. 2004; 53:1137-1144.

53. Lee EJ, Choi C, Park CK, Maeng L, Lee J, Lee A and Kim KM. Tracing origin of serrated adenomas with BRAF and KRAS mutations. Virchows Archiv. 2005; 447:597-602.
54. Kim KM, Lee EJ, Ha S, Kang SY, Jang KT, Park CK, Kim JY, Kim YH, Chang DK and Odze RD. Molecular features of colorectal hyperplastic polyps and sessile serrated adenoma/polyps from Korea. The American journal of surgical pathology. 2011; 35:1274-1286.

55. Fujita $K$, Yamamoto $H$, Matsumoto $T$, Hirahashi $M$, Gushima M, Kishimoto J, Nishiyama K, Taguchi T, Yao T and Oda Y. Sessile serrated adenoma with early neoplastic progression: a clinicopathologic and molecular study. The American journal of surgical pathology. 2011; 35:295-304.

56. Chen D, Huang JF, Liu K, Zhang LQ, Yang Z, Chuai ZR, Wang YX, Shi DC, Huang Q and Fu WL. BRAFV600E mutation and its association with clinicopathological features of colorectal cancer: a systematic review and metaanalysis. PloS one. 2014; 9:e90607.

57. Clancy C, Burke JP, Kalady MF and Coffey JC. BRAF mutation is associated with distinct clinicopathological characteristics in colorectal cancer: a systematic review and meta-analysis. Colorectal disease. 2013; 15:e711-718.

58. Muto T, Bussey HJ and Morson BC. The evolution of cancer of the colon and rectum. Cancer. 1975; 36:22512270 .

59. Snover DC. Update on the serrated pathway to colorectal carcinoma. Human pathology. 2011; 42:1-10.

60. Rex DK, Ahnen DJ, Baron JA, Batts KP, Burke CA, Burt RW, Goldblum JR, Guillem JG, Kahi CJ, Kalady MF, O'Brien MJ, Odze RD, Ogino S, Parry S, Snover DC, Torlakovic EE, et al. Serrated lesions of the colorectum: review and recommendations from an expert panel. Am J Gastroenterol. 2012; 107:1315-1329; quiz 1314, 1330.

61. Comprehensive molecular characterization of human colon and rectal cancer. Nature. 2012; 487:330-337. 